substituição da universalização pela focalização; advogo a necessária complementaridade, sem o quê políticas universais terão grande dificuldade em chegar até os mais necessitados e incidir no acesso e usufruto dos pobres aos direitos constituídos. Não devemos esquecer que a experiência cotidiana dos pobres está constituída por um sem fim de barreiras para conseguir (sobre)viver com dignidade. Assim, a crítica deve também ser direcionada à fragmentação das políticas sociais, mesmo as universais. Apenas políticas intersetoriais, abrangentes, conseguirão impactar na qualidade de vida dos cidadãos.

Apesar de todos esses problemas, o sistema participativo brasileiro em saúde é modelar para outros setores nacionais (assistência social, segurança pública, cidades), na instituição de conselhos e/ou conferências, provocando admiração e respeito internacional e sendo usado como exemplo bem sucedido de processo decisório participativo. E efetivamente conjuga problemas e sucessos, impasses e soluções. A participação social é o veículo privilegiado para, como afirma Paim, conferir "atenção especial para a pluralidade de vozes numa sociedade democrática (o que) permitiria constituir sujeitos políticos individuais e coletivos que questionem a subversão dos direitos sociais, as iniquidades em saúde e as relações de subordinação, desencadeando novas ações políticas". Contudo, para dar vazão às demandas da "pluralidade de vozes", essas instâncias e espaços precisam ser reinventados na sua composição, funcionamento, papel desempenhado.

Atualmente, conselhos e conferências enfrentam desafios que não foram (e nem poderiam ser) previstos no projeto original da Reforma Sanitária. Ao transformismo dos sujeitos políticos, assinalado por Paim, deve-se contrapor a necessária transformação das estruturas e instâncias de participação. Nada nasce pronto, nem gente, nem sistema. Tudo cresce, muda e se transforma. Ou deve crescer, mudar e se transformar. Quando isso não acontece, cristaliza, petrifica, burocratiza e perde o sentido inicial. São nas instâncias de participação social que ainda pulsam a utopia e o desejo de justiça social. É nelas que pode ser formulada, se não um projeto para a Nação, pelo menos, a necessária efetivação do projeto da Reforma Sanitária na sua amplitude e consequência social, como "projeto civilizatório" 7.

1. 14ạ Conferência Nacional de Saúde. Radis 2012; (115):10-33.

2. Escorel S. Saúde: uma questão nacional. In: Teixeira SF. Reforma sanitária: em busca de uma teoria. São Paulo: Cortez Editora/Rio de Janeiro: ABRASCO; 1989.

3. Cortes SV, Gugliano A. Entre neocorporativistas e deliberativos: uma interpretação sobre os paradigmas de análise dos fóruns participativos no Brasil. Sociologias 2010; (24):44-75.

4. Cohn A. Cartas ao presidente Lula: Bolsa Família e direitos sociais. Rio de Janeiro: Pensamento Brasileiro; 2012.

5. Alves H. Programa Bolsa Família, Saúde da Família e Processos de exclusão e inclusão social: um estudo de caso no Município de Silva Jardim (RJ) [Tese de Doutorado]. Rio de Janeiro: Escola Nacional de Saúde Pública Sergio Arouca, Fundação Oswaldo Cruz; 2013.

6. Escorel S, Moreira MR. Desafios da participação social em saúde na nova agenda da reforma sanitária: democracia deliberativa e efetividade. In: Fleury S, Lobato LVC, organizadoras. Participação, democracia e saúde. Rio de Janeiro: Cebes; 2009, p. 229-47.

7. Arouca S. A reforma sanitária brasileira. Tema (proj. Radis) 1988; (11):2-4.

http://dx.doi.org/10.1590/0102-311XCO031013

Ligia Bahia

Núcleo de Estudos de Saúde Coletiva, Universidade Federal do Rio de Janeiro, Rio de Janeiro, Brasil. ligiabahia@terra.com.br

\section{O prazo de validade do SUS}

$\mathrm{O}$ artigo de Paim analisa a gênese do projeto do SUS e a trajetória de sua implementação, elucidando como, quando e quem tornou possível o avanço de incluir o direito à saúde e SUS na Constituição Federal de 1988 e assinala as mudanças de rumo e prumo que os desidrataram. Trata-se de um trabalho acadêmico valoroso e corajoso. A crítica, no sentido estrito do termo, é o melhor antídoto contra as tendências de transformar o SUS em peça de museu.

Vinte e cinco depois e muitas mudanças no país, a pergunta não explicitada sobre o prazo de validade daquele projeto de SUS referido por Paim está no ar. Se o Brasil não é o mesmo, será que o SUS não perdeu o prazo de validade? Em 1988, o Muro de Berlim existia, o papel da China na divisão internacional do trabalho era menos proeminente, não havia previsão da atual crise econômica e os muitos dos brasileiros que formularam o capitulo dos direitos sociais da Constituição eram desenvolvimentistas. Naquele contexto, de saída do regime militar, o texto constitucional foi elaborado antes de se organizarem e disseminarem as instituições e práticas que pretendia produzir. A desagregação do bloco de sustentação da ditadura militar e um processo constituinte marcado por uma intensa e influente participação da sociedade civil organizada e disputas de hegemonia permitiram que o proje- 
to da Reforma Sanitária subsidiasse o conteúdo do capítulo da ordem social na Constituição de 1988.

Logo após a Constituição, o panorama político foi delineado pelos sucessivos fracassos das tentativas de conter a inflação e acirrada competição pelos fundos públicos. A década 1980 não foi a do ajuste estrutural, embora as recomendações de ajuste fiscal do Banco Mundial e suas adequações à política de saúde já estivessem consolidadas em 1987 1. O adiamento do ajuste evitou que o contraste entre a adoção de uma política claramente recessiva e as demandas por participação e direitos de cidadania questionasse o próprio processo de redemocratização 2 .

Foi no governo FHC que o bloco hegemônico PSDB-PFL iniciou a superação do modelo denominado desenvolvimentista mediante uma política de controle da inflação e recessão. E os opositores das reformas neoliberais passaram a defender com afinco a preservação do conteúdo da Constituição. Tais controvérsias em torno da importância e legitimidade da Constituição, bem como a não realização da então propalada revisão da Constituinte em 1993 conferiram-lhe um status de referência compartilhada pelas forças políticas da situação e da oposição.

Analogamente, o SUS, tido pelos adeptos das reformas orientadas pelo mercado como um fóssil pré-histórico, também se tornou o centro de gravitação do sistema de saúde brasileiro. Contudo, sua construção institucional foi circunscrita por um ambiente institucional desfavorável às políticas sociais universalistas. O pacto estabelecido de preservação das desigualdades, inclusive na saúde, viabilizou-se por políticas fiscais, que restringiram dramaticamente os fundos públicos alocados democraticamente. Esses dispositivos tolheram duplamente o financiamento para o SUS. O primeiro instrumento de racionamento de recursos para as políticas sociais está vinculado ao fato de que a parcela do orçamento público relativa ao pagamento da conta de juros não é objeto do debate em nenhuma instância do Poder Legislativo ou dos órgãos de controle. Mesmo a submissão da renovação da DRU (desvinculação de receitas da União), ao Congresso Nacional, embora sempre cause algum frisson, jamais chegou a se constituir como ponto realmente polêmico no âmbito das cúpulas dos três poderes republicanos. Restou às áreas sociais concorrer entre si por nacos do fundo público, por meio da definição de percentuais, que por sua vez cristalizam a fragmentação da qual se tentou escapar com a inclusão na Constituição da Seguridade Social. O segundo mecanismo refere-se aos subsídios e deduções fiscais para a oferta e demanda por planos e serviços privados de saúde. A conjugação de ambos os dispositivos é perversa porque o subfinanciamento do SUS, aliado ao reforço de recursos para os serviços privados, mantém diferenciais de acesso e utilização de serviços financiados pelo fundo público.

Tal retrospecto esquemático pode auxiliar a compreensão de eventuais traços distintivos das reformas do período FHC e o momento atual. Entretanto, o estudo de Paim, em decorrência do referencial teórico e dos objetivos traçados, não demarca clivagens entre as coalizões governamentais nucleadas pelo PSDB e pelo PT, mas menciona a literatura que assinala as rupturas com o neoliberalismo, que teriam sido efetivadas desde o primeiro governo Lula (especialmente durante o segundo mandato, e o aprofundamento das medidas denominadas neodesenvolvimentistas no governo Dilma), e assinala também as críticas a essas interpretações. Essa polêmica, embora possa empolgar o debate em fóruns governamentais, de fato não tem uma tradução acadêmica imediata para os estudiosos do sistema de saúde brasileiro.

Objetivamente, "todos os governos prestaram alguma contribuição ao SUS” e simultaneamente “[fabricaram] 'crises' da Previdência Social". Ou seja, essencialmente a política social passou a ser conduzida por meio de políticas verticalizadas e emergenciais e programas de transferência condicionada de renda e, a partir dos governos do PT, mediante ainda o reforço ou a institucionalização de políticas identitárias, como por exemplo, a promoção da Secretaria dos Direitos das Mulheres ao estatuto de ministério e o estímulo às cotas raciais nos cursos de ensino superior e a criação da Secretaria de Promoção da Igualdade Racial. Esse padrão de submissão da política social à lógica economicista manteve-se praticamente intacto ao longo dos governos eleitos democraticamente. Os conceitos de "transformismo na saúde" e a "hegemonia às avessas", convocados por Paim, decifram os "aparentes paradoxos" de governos que "defendem" o SUS, mas implementam políticas cumulativas de privatização. $\mathrm{O}$ economicismo ${ }^{3}$ não perdeu o prazo de validade, a doutrina cujo principal cânone é a eficiência alocativa do mercado para tudo e todos tem sido a fonte de inspiração para a implementação de políticas públicas de privatização da saúde (exigentes de forte intervenção estatal).

A novidade são as profundas mudanças que ocorreram, a partir do inicio dos anos 2000, em função da incorporação de milhões de trabalhadores à base da pirâmide ocupacional urbana, especialmente nos serviços. A mobilidade social desse imenso contingente populacional, recém inscrito em extratos superiores de renda, consumo e formalização no mercado de trabalho, atu- 
aliza o debate sobre o sistema de proteção social. A expressiva parcela de postos de trabalho informais era um elemento estrutural que diferenciava o Brasil dos países com sistemas universais. Esse fenômeno revitaliza o debate sobre o sistema de proteção social. Os mesmos especialistas que desde o governo FHC exercem forte influência e levam adiante as políticas focalizadas, nesse momento ocupam cargos no Instituto de Pesquisa Econômica Aplicada (IPEA) e postulam que o fato de termos nos tornado um "país de classe média" induz à privatização da saúde 4 . A relação causal seria intuitiva, a melhoria da renda individual e familiar induz a opção por alternativas assistenciais personalizadas, customizadas, de qualidade superior, portanto privadas.

No restante do mundo, a ascensão das massas trabalhadoras a melhores condições de vida originou tanto sistemas públicos de saúde robustos quanto a portentosa indústria de seguros saúde nos Estados Unidos. Portanto, as previsões sobre a inclinação natural do sistema brasileiro de saúde pelo mercado, não se baseia nem nas coisas da lógica nem na lógica das coisas e sim numa extravagante mistura de dois ingredientes: a tentativa de comprovar a existência de uma "nova classe média” mediante a exibição do aumento das coberturas de planos de saúde como indicador de mudança de status de classe social com as intenções de agentes do mercado de expandir seus negócios. Logo, o Brasil não está predestinado à privatização da saúde. Os manifestantes que foram às ruas recentemente reafirmaram suas "preferências" pelo SUS.

Em 1988, Francisco de Oliveira escreveu um artigo seminal intitulado O Surgimento do AntiValor 5 , no qual procura distinguir a marca do Estado de Bem-Estar Social no capitalismo. Seu principal argumento é o sistema de proteção social constitui um segundo momento do desenvolvimento do capitalismo. A diferença não recai sobre o uso de subsídios e auxílios públicos, na medida em que a vasta gama de suportes financeiros estatais para diversos setores e atividades é uma marca do próprio capitalismo ${ }^{6}$. A formação do sistema capitalista seria impensável sem a utilização de recursos públicos. Para este autor, o Welfare State representa uma "revolução copernicana”, nas relações estabelecidas entre trabalho e capital porque o fundo público passa a desempenhar uma função ex-ante das condições de reprodução de cada capital particular e das condições de vida, em lugar de seu caráter $e x$ post típico do capitalismo concorrencial.

Os argumentos dos neoliberais e de retóricos antineoliberais se fundamentam nas teses sobre os malefícios da redistribuição dos resultados da produção social mediante extração de recursos

para o fundo público sobre os investimentos privados. Porém é essa voracidade que, deixada entregue a si mesma, desnatura a democracia e o sentido de igualdade nela inscrito desde os tempos modernos. Ao nos convidar para remar contra as iniquidades em saúde e desencadear novas ações políticas, Paim nos leva a (re)conhecer os imensos esforços teóricos que embalaram o projeto do SUS constitucional. Reinventá-lo é tarefa para muitos e requer estudar profundamente a demarcação da utilização e distribuição da riqueza pública para "desencadear novas ações políticas".

1. World Bank. Financing health services in developing countries: an agenda for reform. Washington DC: World Bank; 1987.

2. Nobre M. Indeterminação e estabilidade: os 20 anos da Constituição Federal e as tarefas da pesquisa em direito. Novos Estudos 2008; (82):97-106.

3. Polanyi $\mathrm{K}$, organizador. A subsistência do homem e ensaios correlatos. Rio de Janeiro: Contraponto; 2012.

4. Secretaria de Assuntos Estratégicos. Presidência da República. Vozes da classe média: é ouvindo a população que se constroem políticas adequadas. http://www.sae.gov.br/site/?p=13433.

5. Oliveira F. O surgimento do anti-valor: capital, força e trabalho e fundo público. Novos Estudos 1988; (22):8-28.

6. Barr N. Economics of the welfare state. London: Oxford University Press; 2012.

http://dx.doi.org/10.1590/0102-311XCO041013

Ana Luiza d'Ávila
Viana

Faculdade de Medicina, Universidade de São Paulo, São Paulo, Brasil. analuizaviana@usp.br

\section{Longos dias têm cem anos}

Refletir e escrever sobre o lúcido artigo de Paim, após os episódios de junho/julho de 2013, introduz dupla responsabilidade: primeiro, comentar e refletir sobre os paradoxos e perguntas expostas pelo texto; segundo, lê-lo com uma perspectiva histórica, incluindo uma pequeníssima história, apenas do ponto de vista do tempo, os acontecimentos recentes.

Qualquer dia antes e após as manifestações de massa de junho/julho parece separar um longo espaço de tempo, quase uma eternidade, semelhante ao adágio "longos dias têm cem anos", título do romance de Augustina Bessa-Luís 1, escritora portuguesa contemporânea.

A ideia do adágio, conhecida expressão popular portuguesa, expressa que determinadas coisas levam tempo para maturar, o que pode 